\title{
Development of a HEC-RAS Sediment Model for the Chippewa River, Wisconsin for Use in Predicting Future Dredging Activities
}

By Alex Nelson

PURPOSE: This U.S. Army Corps of Engineers (USACE) Regional Sediment Management Technical Note (RSM-TN) describes the process of constructing and calibrating a sediment model that utilizes recent sediment data collection efforts performed by the U.S. Army Engineer Research and Development Center - Coastal and Hydraulics Laboratory (ERDC-CHL) and the U.S. Geological Survey (USGS) along the Chippewa River in Wisconsin. A USACE Institute for Water Resources (IWR), Hydrologic Engineering Center, River Analysis System (HEC-RAS, version 5.0.7) unsteady flow sediment model was developed to perform a continuous simulation of bedload and suspended load transport and dredging operations through the Chippewa River and Lower Pool 4 of the Upper Mississippi River navigation channel. The resulting model developed through this effort can be useful in forecasting future channel maintenance needs through this reach of river.

INTRODUCTION: The USACE St. Paul District (MVP) maintains approximately 244 miles of navigation channel and operates 13 lock and dam sites along the Upper Mississippi River (UMR) in order to achieve the goals of the "9-Foot Channel Project," which was authorized as part of the 1930 Rivers and Harbors Act to provide a channel of sufficient depth and width suitable for longhaul common-carrier service (USACE 2019). In order to maintain the channel within the MVP navigation boundaries, an average of over 900,000 cubic yards of material must be removed annually through dredging operations. In recent years, the 5-year average dredging quantities have exceeded 1,000,000 cubic yards. Of this total quantity, a large portion of the annual dredging needs are located in Lower Pool 4, which is the ten mile river reach located immediately downstream of the Mississippi River confluence with the Chippewa River. Upstream of the Chippewa River is Lake Pepin, a 23-mile long natural riverine lake which traps all sand and silt sized particles. Because of this, the sediment delivered to Lower Pool 4 is almost completely sourced from the Chippewa River. Even though this reach of the UMR makes up only 4\% of the total MVP navigation channel length, the average annual dredging requirement of roughly 270,000 cubic yards make up over $30 \%$ of MVP's annual channel maintenance (Figure 1). 


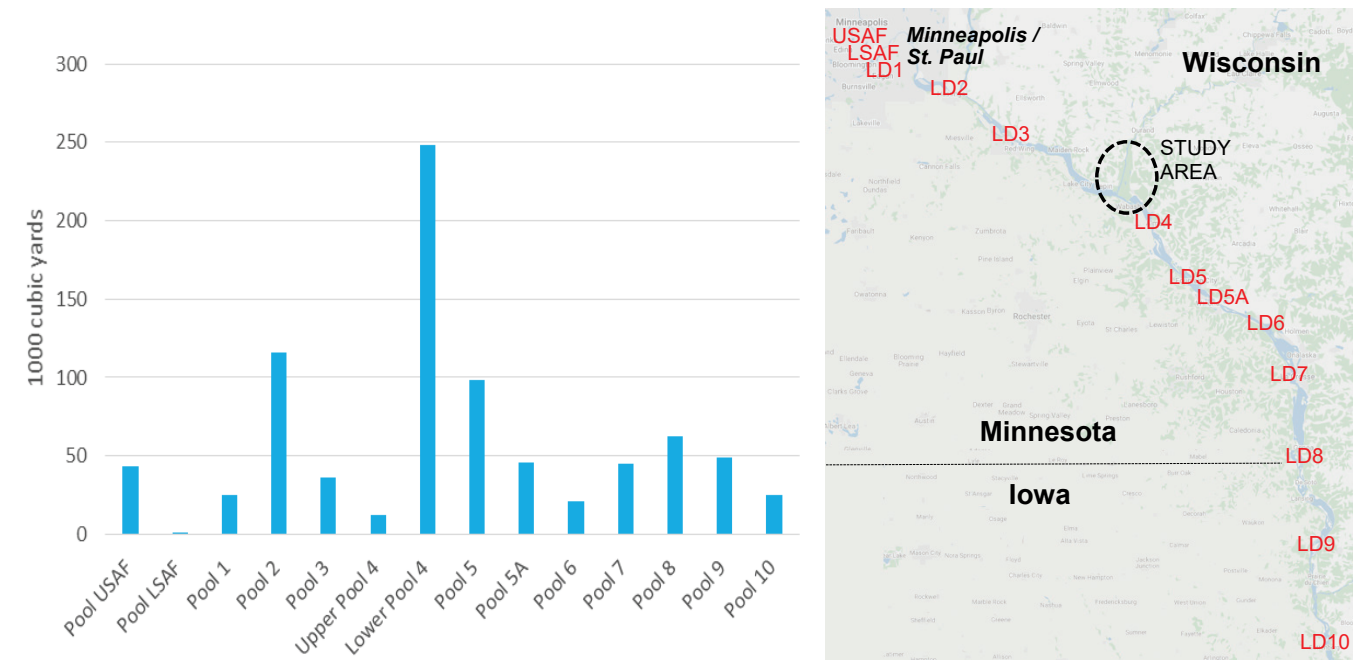

Figure 1. Average annual dredge volumes in St. Paul District, 1974-2015, and map of Navigation Pools throughout St. Paul District.

Sediment on the Chippewa River has been a source of study by both USACE and USGS in recent decades. In 1992, the USGS released a technical report that summarized particle sizes and loads on the Chippewa River and other rivers in Wisconsin from the period of 1976-1983 (Rose 1992). This USGS effort was funded by USACE. The purpose of this report in regards to the Chippewa River was to summarize all the recent bed-load and suspended load information, such as flow-load relationships and particle size distributions, as well as to describe some of the hydraulic relationships along the delta of the Chippewa River near the confluence with the UMR. One of the primary conclusions included in this report was that along the lower reach of the Chippewa River, the average annual sediment load at Durand, WI was estimated to be 1,073,000 tons per year $(61 \%$ bed-load) and further downstream at Pepin, WI was estimated to be 940,000 tons per year (44\% bed-load). The report further explored the distribution of water and sediment across the Chippewa River delta side channels by developing expected relationships between the total discharge and the discharge experienced in the east, west, and main channels. More recently, the USGS initiated a study that utilized state-of-the-art techniques to provide real-time monitoring of suspended sediment using a bridge mounted multi-frequency array of side-looking Acoustic Doppler Velocity Meters (ADVMs) and bed-load through bridge mounted scour monitors to continuously measure dune profiles. ${ }^{1}$ Acoustic bed-load measurements will be compared to physically collected bed load samples and a theoretical model (Modified Einstein Procedure). Through these methods, sediment data at the monitoring locations can be provided in real-time (15-min increments). In a parallel effort, USACE (Abraham et al. 2019) has completed bed-load transport measurements at various sites on the Chippewa River through the Integrated Section Surface Difference Over Time, Version 2 (ISSDOTV2) method. This method computes bed load transport in sand bed rivers by using sequential multi-beam bathymetric surveys of dune fields. The final results of this effort include a developed relationship between flow and bed load.

${ }^{1}$ https://www.usgs.gov/centers/sbsc/science/measuring-suspended-sediment-concentrations-grain-sizes-andbedload-using?qt-science_center_objects=0\#qt-science_center_objects 
Due to the wealth of available sediment, dredging, and hydrologic data for this reach of river, this site was identified as an excellent candidate for development of a sediment transport model. The modeling approach will be similar to a previous modeling effort of the Mississippi River from Minneapolis, MN through Lake Pepin to determine the impact of various channel maintenance strategies after the lock closure at Upper St. Anthony Falls (Nelson 2019). This approach utilizes a long record of hydrologic data and sediment data in a 1D unsteady, sediment transport model to quantify relative differences in dredging through changed operations, such as halting dredging in the upper pools. A similar approach can be employed in this effort for the Chippewa River to develop the model as a tool that assesses and forecasts future sediment loading conditions and impacts associated with system modifications or operations.

METHOD: The first source of data for developing the hydraulic model was the numerous historic USGS and USACE gage records. These sites have decades of daily and sub-daily observations for measurements like water surface elevation (WSE), flow $\left(\mathrm{Q}_{\mathrm{w}}\right)$, sediment load $\left(\mathrm{Q}_{\mathrm{s}}\right)$, and temperature $(\mathrm{T})$, as well as periodic field measurements of water surface and flow to verify gage rating curves. A summary of the gages utilized for this effort is shown in Table 1.

\begin{tabular}{|l|l|l|l|l|l||}
\hline \multicolumn{6}{||c|}{ Table 1. Summary of gage data utilized in Lower Pool 4 and the Chippewa River. } \\
\hline \hline \multicolumn{1}{|c|}{ River } & \multicolumn{1}{|c|}{ Gage } & \multicolumn{1}{|c|}{ Data } & From & To \\
\hline Chippewa & USGS 05369500 & Durand, WI & WSE, $Q_{w}, Q_{s}, T$ & 1974 & Present \\
\hline Chippewa & USGS 05371200 & Pepin, WI & Field Measurements & 1976 & Present \\
\hline Mississippi & USGS 05355341 & Reads Landing & Q $_{w}$, Field Measurements & 2015 & 2018 \\
\hline Mississippi & LD3 & Red Wing, MN & WSE, $Q_{w}$ & 1959 & Present \\
\hline Mississippi & LD4 & Alma, WI & WSE, $Q_{w}$ & 1959 & Present \\
\hline \hline
\end{tabular}

With these gages in mind as boundary conditions and calibration points for the model, a model geometry was constructed to cover a domain that could capture the relevant hydrodynamic and sediment processes in the area without creating excessive computational demands. The ultimate extent of the model domain, covering the Chippewa River downstream of Durand, WI and the Mississippi River between Lake Pepin and Lock and Dam No. 4, is shown in Figure 2. 


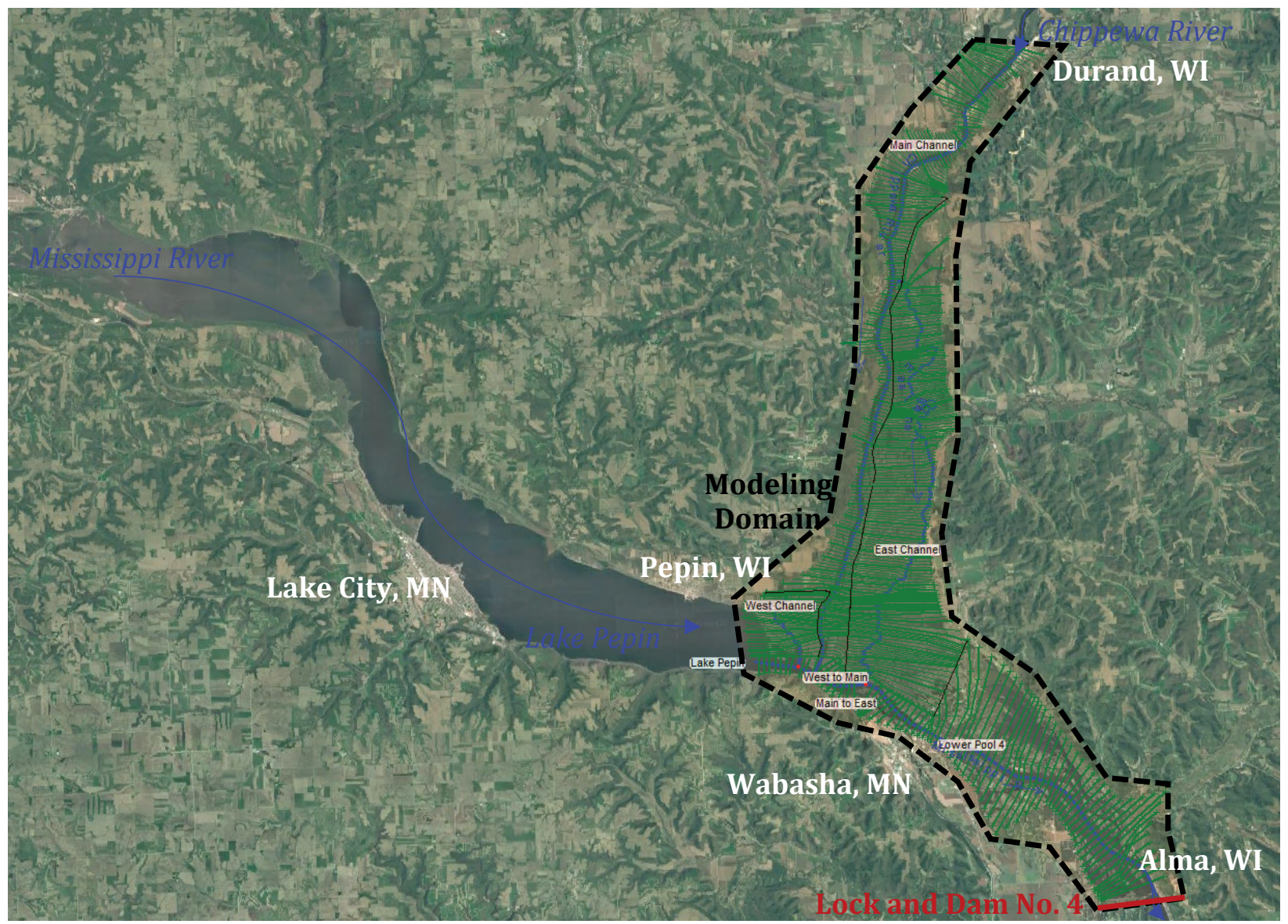

Figure 2. Final model domain selected for the 1D Chippewa River modeling.

Due to the complexity of flows through the Chippewa River delta, the 1D river channel was separated into three parallel reaches: the main channel, the east channel, and the west channel. These hydraulic reaches were then connected to each other with "lateral structure" features, which can pass flow and sediment back and forth between the reaches. Each of these parallel reaches then pass downstream to different points along the Mississippi River. While the upstream ends of the Chippewa and Mississippi Rivers include inflow boundary conditions, the downstream boundary is specified at Lock and Dam No. 4 through a water surface elevation boundary condition.

The primary source of elevation data for the model geometry is LiDAR data collected through efforts by the State of Minnesota and the State of Wisconsin. Much of this data has been combined with Mississippi River bathymetric data in the form of seamless elevation datasets, as LiDAR data is only available above the water surface elevation at the time of the data collection. In using the seamless data set, cross-sections can be cut directly from the terrain model for use in the hydraulic model. Not included in this seamless dataset are the bathymetric data for the Chippewa River main channel and side channels, which were incorporated into the model by modifying the terrain with estimated channel dimensions and through modification of the channel Manning's n-values.

In the spring of 2019, extended high water on the Chippewa River allowed for a rare opportunity for USACE to collect additional data for model construction and calibration. During the portion of the year that is typically suitable for collecting data in a northern climate, the Chippewa River is generally difficult to navigate by boat due to the extensive presence of sandbars. In 2019, 
however, moderately high flows remained for an extended period that allowed both the St. Paul District bathymetric survey crew and the hydraulic section technician to traverse the river to collect various types of data. The bathymetric crew were able to obtain cross-section survey points, longitudinal profile surveys, and water surface elevation data. The hydraulic technician was able to gather flow measurement data to capture the flow split between the main channel and the side channels of the Chippewa River. This data was useful for model construction in supplementing additional channel data in areas where there was no previous bathymetry. The data was also valuable for model calibration by providing a detailed water surface profile and an estimate of flow splits for the "lateral structure" connection calibration.

Once the final bathymetric source was incorporated into the geometry, the model was calibrated at gages and survey observations primarily through adjusting Manning's n-values, weir coefficients, and ineffective flow limits. Table 2 shows the calibrated n-values.

\begin{tabular}{|c|c|c|}
\hline \multicolumn{3}{|l|}{ Table 2. Final calibrated Manning's n-values used in the model. } \\
\hline \hline River & Channel n-value & Overbank n-value \\
\hline Chippewa River & 0.024 & 0.06 \\
\hline East Channel & 0.035 & 0.045 \\
\hline West Channel & 0.025 & 0.06 \\
\hline Mississippi River & 0.026 & 0.06 \\
\hline
\end{tabular}

The roughness values are fairly similar to previous modeling efforts such as the UMR FlowFrequency Study (USACE 2004). The one channel that is modeled slightly different than the others is the East Channel. Both the East and West Channels included some estimate of underwater channel bathymetry, however, there were limited survey points available in those areas. Rather than iteratively modifying the terrain to achieve the appropriate conveyance through the East Channel, the channel n-value was modified to allow the estimated channel to convey the appropriate amount of flow. Through this calibration, Figure 3 shows the longitudinal profile of the Chippewa River comparing modeled to observed water surface (OWS) on 1 May 2019, the date of the survey.

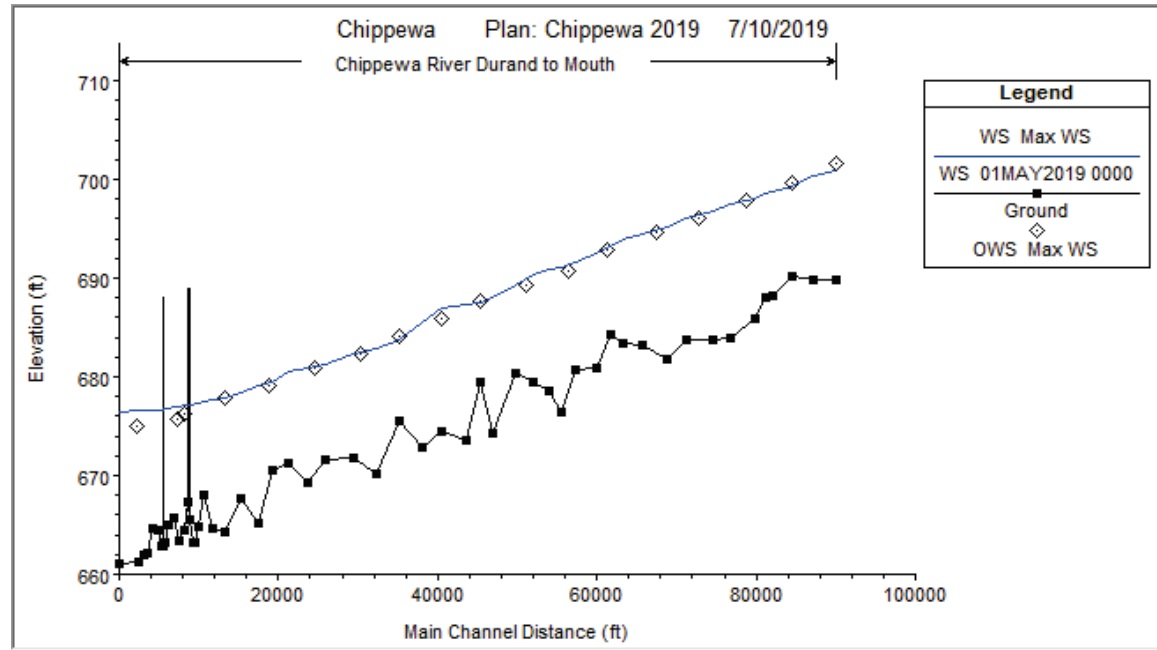

Figure 3. Calibrated water surface profile compared to observed elevations along the Chippewa River. 
Calibration of the hydraulic model was also performed through validating the relationship of the Chippewa delta flow split that was previously identified by the USGS (Rose 1992). Calibration was balanced between matching the Chippewa River main channel water surface profile to the 1 May 2019 water surface elevation profile observations, and capturing the appropriate flow split between the bridge openings that cross the three channels along Wisconsin State Highway 35. Figure 4 shows the eight bridge openings in relation to each channel as they cross Highway 35 and the modeled flow-split relationships from the USGS (lines) and from this effort (points).

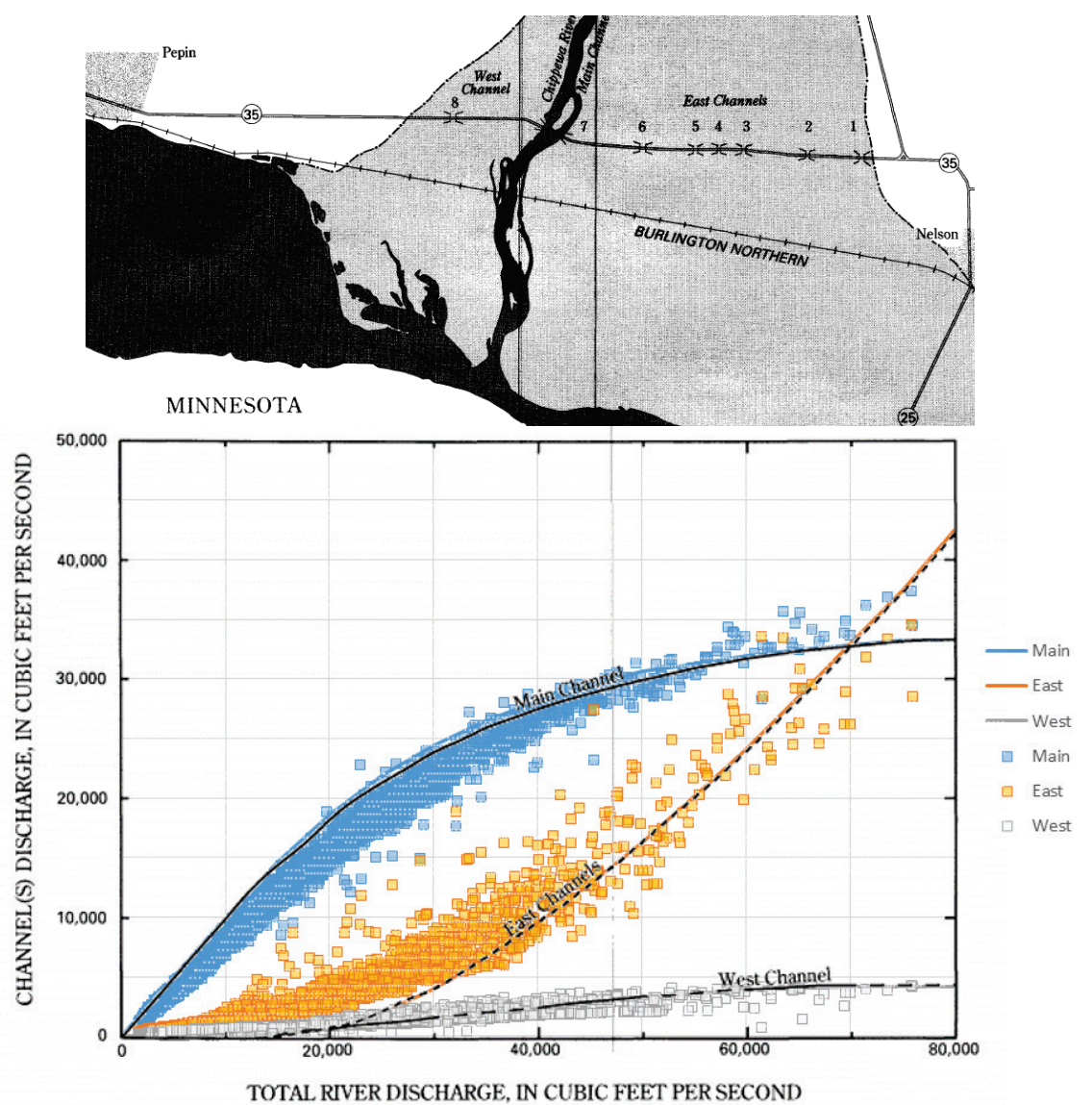

Figure 4. USGS reported flow splits (black solid and dashed lines) compared to modeled flow splits (blue, yellow, and grey square point features).

Figure 4 shows the entire modeled record (1974-2019) of daily flows for each modeled channel of the Chippewa River compared to the developed USGS relationships. The final model calibration shows strong agreement with the USGS relationships where, as the total discharge approaches $60,000 \mathrm{cfs}$, more flow is typically being conveyed through the East and West Channels rather than in the main channel. While the model may overestimate flow through the East Channels for total discharges below 40,000 cfs, overall the model appears to be capturing the physical behavior of the system reasonably well. The model shows some of the variability of the flow split relationships (rather than just the best fit line from the USGS); however, these are likely a result of the fixed bed assumption and the changes in tailwater conditions on the Mississippi River. The system may have an even wider range of variability when accounting for seasonal variation in vegetation and ice and due to the mobile bed elevation of the channels. 
With strong hydraulic model calibration and validation, the modeling framework can be extended to include sediment transport by incorporating sediment boundary conditions, sediment sizes and characteristics, transport functions, and dredging routines into the model.

RESULTS: There are dozens of inputs that need to be added to the hydraulic model to simulate sediment through the system including, at a minimum: bed gradation at each cross-section, movable lateral limits and maximum depth at each cross-section, sediment flow-load relationships and gradations at each inflow location, and a transport function, sorting method, and fall velocity method. In addition to these basic requirements, various options can be modified beyond the default settings. While the sediment calibration process explored modifying the full range of these inputs, only the final parameters, found in Table 3, are summarized in this report.

\begin{tabular}{|c|c|}
\hline Sediment Parameter & Selected for Model \\
\hline Transport Function & Laursen (Copeland) \\
\hline Sorting Method & Active Layer \\
\hline Fall Velocity Method & Dietrich \\
\hline Movable Bed Limits & Set to bank stations \\
\hline Maximum erodible depth & $\begin{array}{l}2 \text { feet for the Chippewa River, } 5 \text { feet for side channels, } 0 \text { feet for } \\
\text { the Mississippi River, } 0 \text { feet in the overbanks }\end{array}$ \\
\hline $\begin{array}{l}\text { Grain Class Size, Weight, } \\
\text { Effective Depth }\end{array}$ & Defaults \\
\hline Cohesive Options & $\mathrm{N} / \mathrm{A}$ \\
\hline Bed Change Options & $\begin{array}{l}\text { No Bed Change Allowed Outside of the Movable Limits (Non- } \\
\text { erodible Overbanks) }\end{array}$ \\
\hline Routing Method & Limit to Water Velocity \\
\hline Modify Transport Functions? & $\mathrm{N} / \mathrm{A}$ \\
\hline Lateral Weir Options & Q weighted for sizes less than Medium Sands \\
\hline BSTEM & N/A \\
\hline Bed Mixing Options & Active layer thickness: d90 \\
\hline Bed Gradation & $\begin{array}{l}0 \% \text { finer than sand, } \sim 50 \% \text { fine to medium sand, } 40 \% \text { medium to } \\
\text { very coarse sand, } 10 \% \text { gravel }\end{array}$ \\
\hline Water Temperature & $\begin{array}{l}\text { Weekly averages, } 33 \text { degrees minimum in winter, } 80 \text { degrees } \\
\text { maximum in summer }\end{array}$ \\
\hline Time Step & 1 hour (6 minute adaptive time step during specified periods) \\
\hline
\end{tabular}

Dredging rules were applied to the Mississippi River below the confluence of the Chippewa River by specifying a width, elevation, and date of dredging to each appropriate cross-section. These extents were set to the approximate maximum extent of dredging through this reach, based on the Lowest Controlled Pool (LCP) elevations (i.e. the lowest possible pool elevation at a given location based on the operating curve at Lock and Dam 4), and the historic mapped dredging reaches. It should be noted that this methodology does not necessarily replicate the dredge volumes removed for the dredging events, but does create the appropriate elevations. The elevation was set to $12 \mathrm{ft}$ below the LCP, between elevations 654.6 and $654.1 \mathrm{ft} \mathrm{NAVD88,} \mathrm{to} \mathrm{represent} \mathrm{the} \mathrm{maximum} \mathrm{depth}$ that is dredged to maintain the 9-ft navigation channel. The extents were set based on widths determined from the historic mapped dredged areas, shown as the orange boxes in Figure 5. The typical values, ranging from $300 \mathrm{ft}$ to $600 \mathrm{ft}$, reflect the Lower Pool 4 Dredge Material Management Plan (DMMP), which requires the navigation channel to have a minimum width of $300 \mathrm{ft}$ and $500 \mathrm{ft}$ along bends (USACE 2017). The wider section of up to 1,600 ft represents the 
Chippewa River sediment trap, which is dredged to a wider extent to provide more efficient channel maintenance operations at a designated location. The date set for each year was 1 July, even though dredging can occur throughout the spring, summer, and fall. Since the prescribed dredging is set to the maximum extents and the date is set to a single day, it is expected the model will not have high precision in any given year; however, over time the model should adequately capture cumulative dredging quantities.

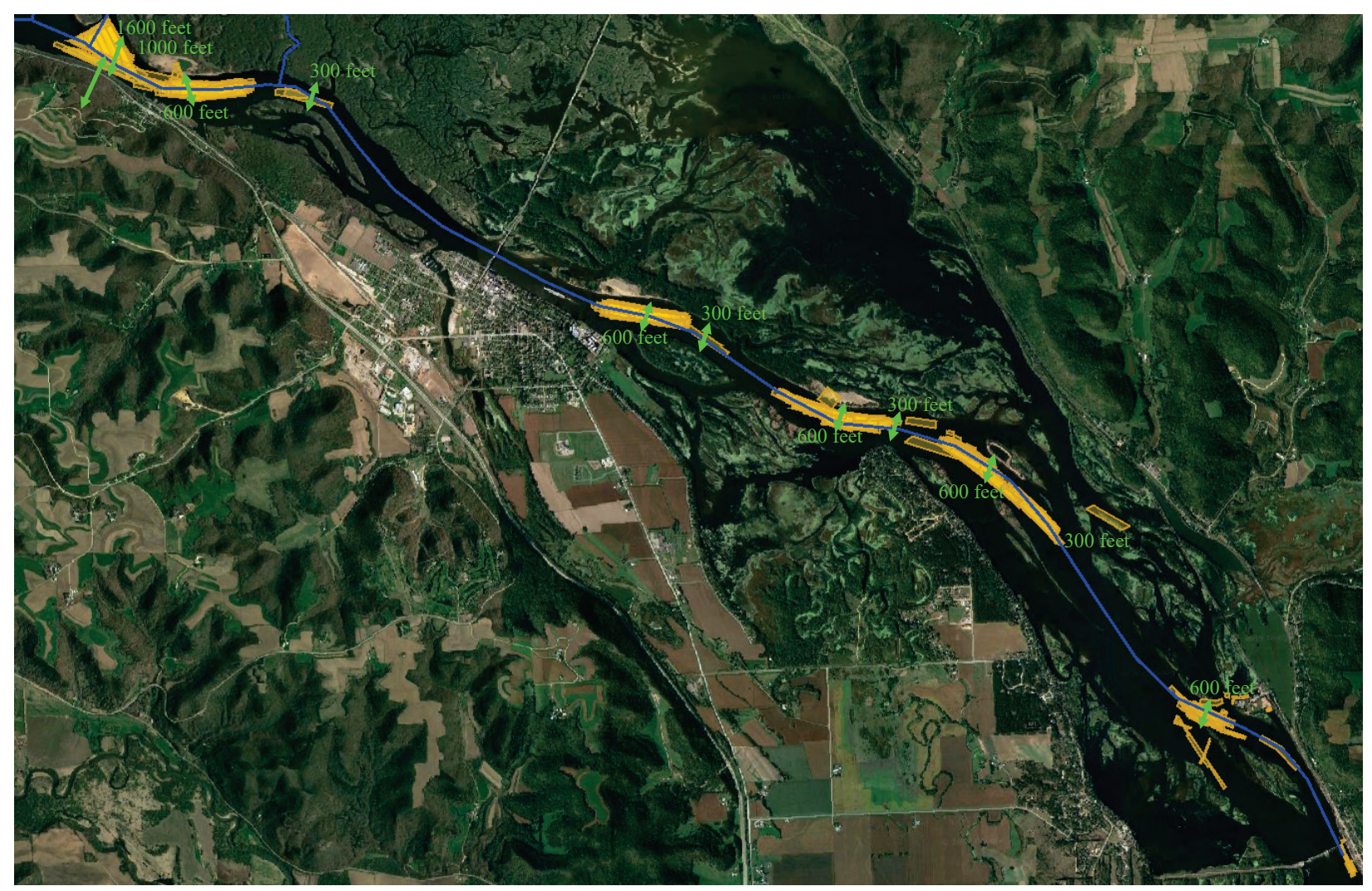

Figure 5. Historic dredge cuts (in orange) and approximate maximum extents of dredging used in the model (in green).

The primary source of calibration for this effort was to modify the flow-load relationship and the flow-load gradations until specified dredging rules resulted in dredge quantities that were similar in magnitude to the historic measured dredging quantities. The amount of medium and coarse sands, as well as the rating of total load (including suspended and bed-load), were increased to a point at which the modeled dredged material was representative of the measured quantities. While this increase was approximately a factor of two times the best fit lines for the flow-load relationships, the calibrated relationships still fell within the spread of data from the USGS and ISSDOTv2 observations. Possible reasons for the required increase in sediment to achieve calibration may be related to potential bias in power fit estimates of the mean value (Ferguson 1986) as well as the potential for significant unmeasured load. Figure 6 shows the calibrated total load curve and the scaled up suspended load and bed-load curves compared to the observed data. Figure 7 shows the model assumption that the total load increases in grain size for higher discharges, reflecting the greater portion of bed-load that makes up the total load for those high flows. 


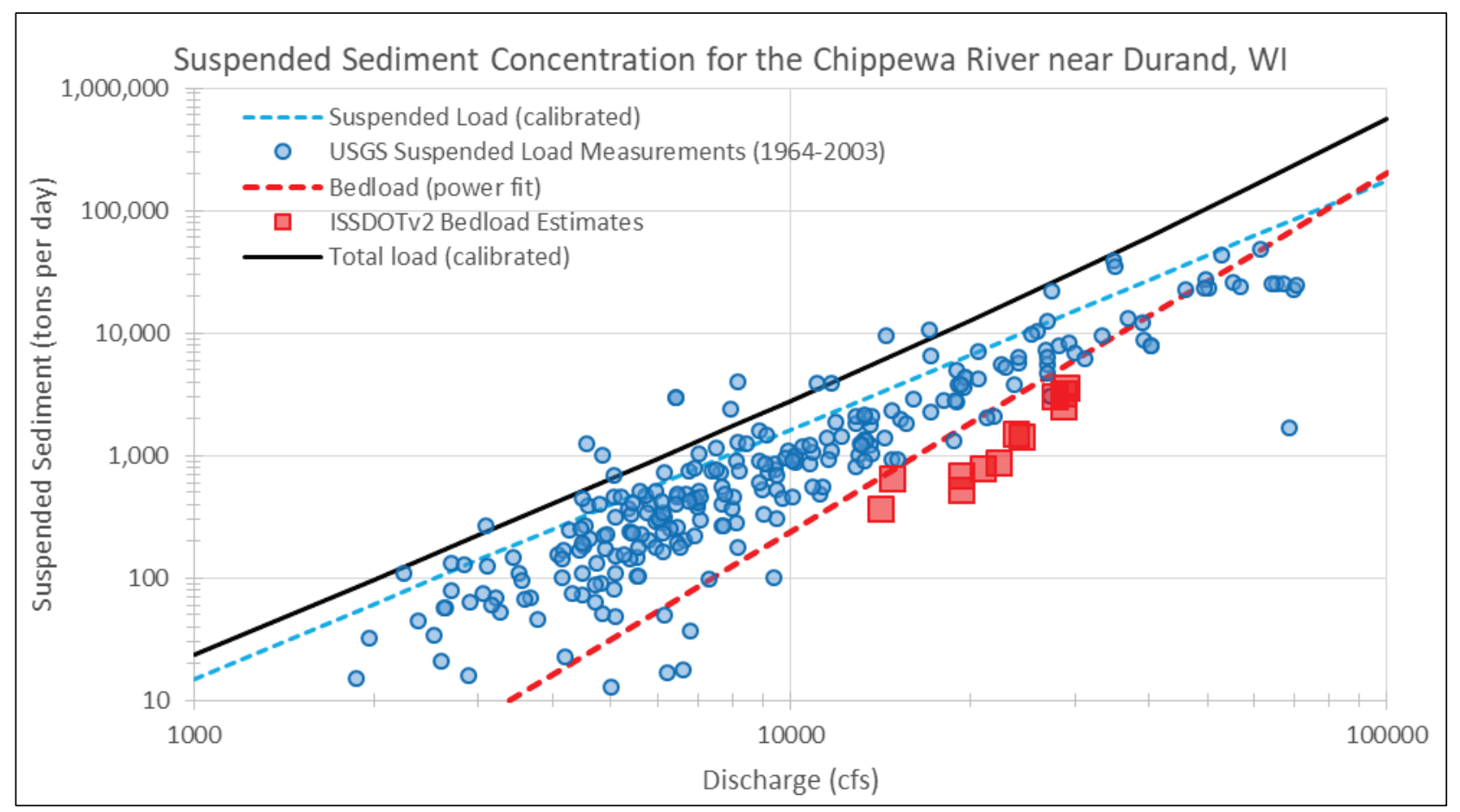

Figure 6. Calibrated suspended load, bed-load, and total load compared to measured values on the Chippewa River at Durand, WI.

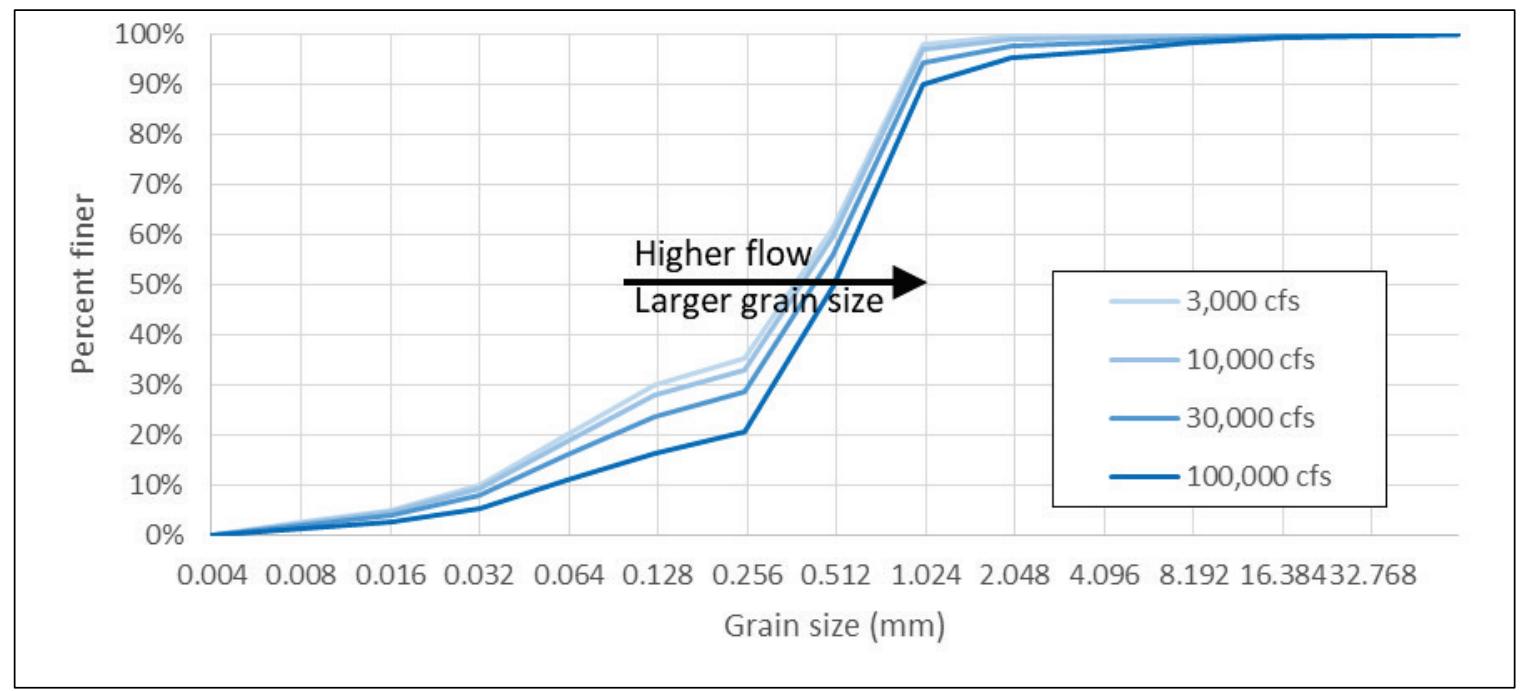

Figure 7. Assumed total load gradations for various flows at Durand, WI.

The final calibrated model was setup to generate detailed output on a monthly basis, including cumulative volume of dredging quantities in cubic yards. These dredging quantities were totaled for the entire Lower Pool 4 on an annual basis after the "1 July" dredging event in order to compare against the annual measured dredging quantities. The modeled dredge volume was compared to the measured quantity on both an annual basis and cumulative basis, as shown in Figure 8 . 


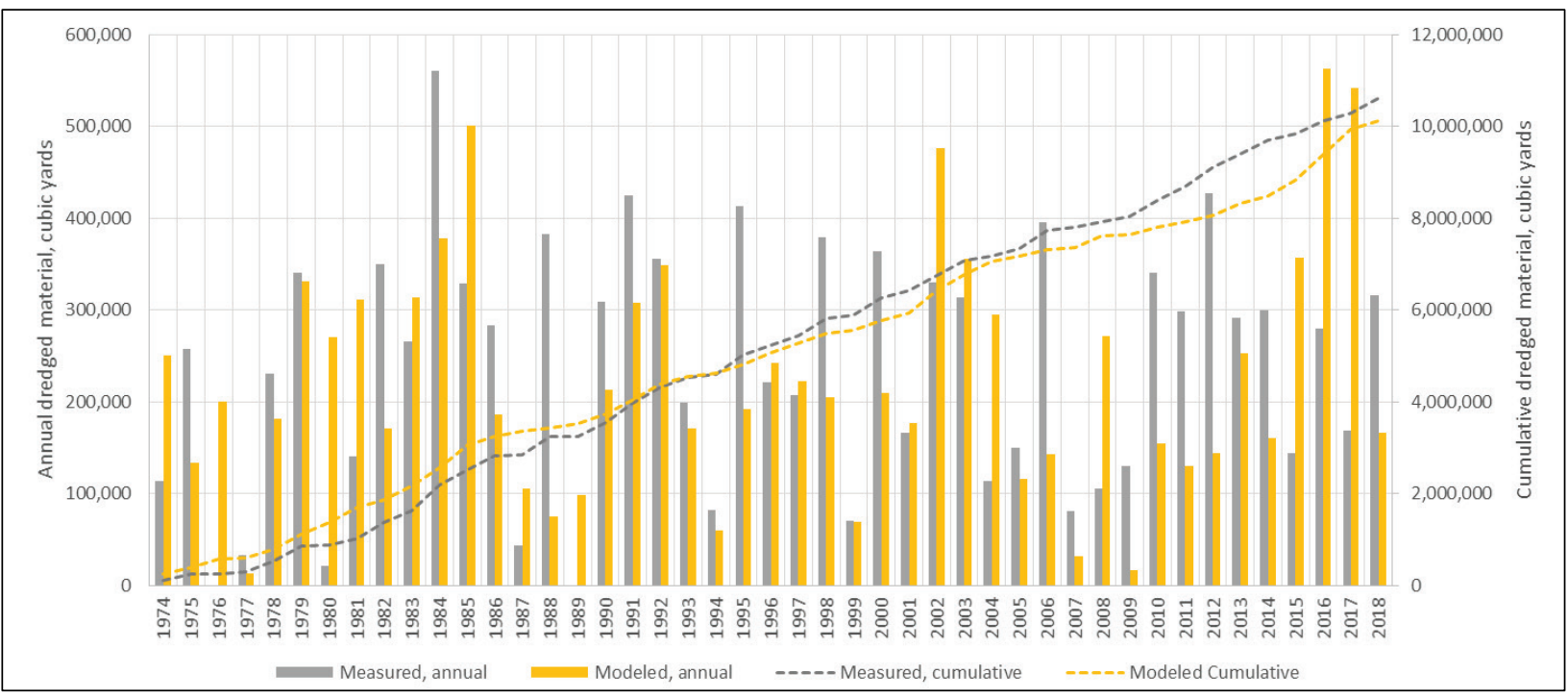

Figure 8. Annual and cumulative dredging quantities, measured vs. modeled, in Lower Pool 4.

Due to the inherent instabilities in HEC-RAS modeling over long periods of record, the modeling period was split into seven smaller periods to be run consecutively to cover the period from 19742018. It is estimated that "restarting" the model numerous times over the simulation may introduce some additional amount of error, but overall, there are not drastic discrepancies found in the results during these periods. On an annual basis, the amount of error varies from $1 \%$ to greater than $100 \%$. When looking at longer periods, the total cumulative error is only $5 \%$ for the entire period and is generally below 50\% over five year periods, as shown in Figure 9.

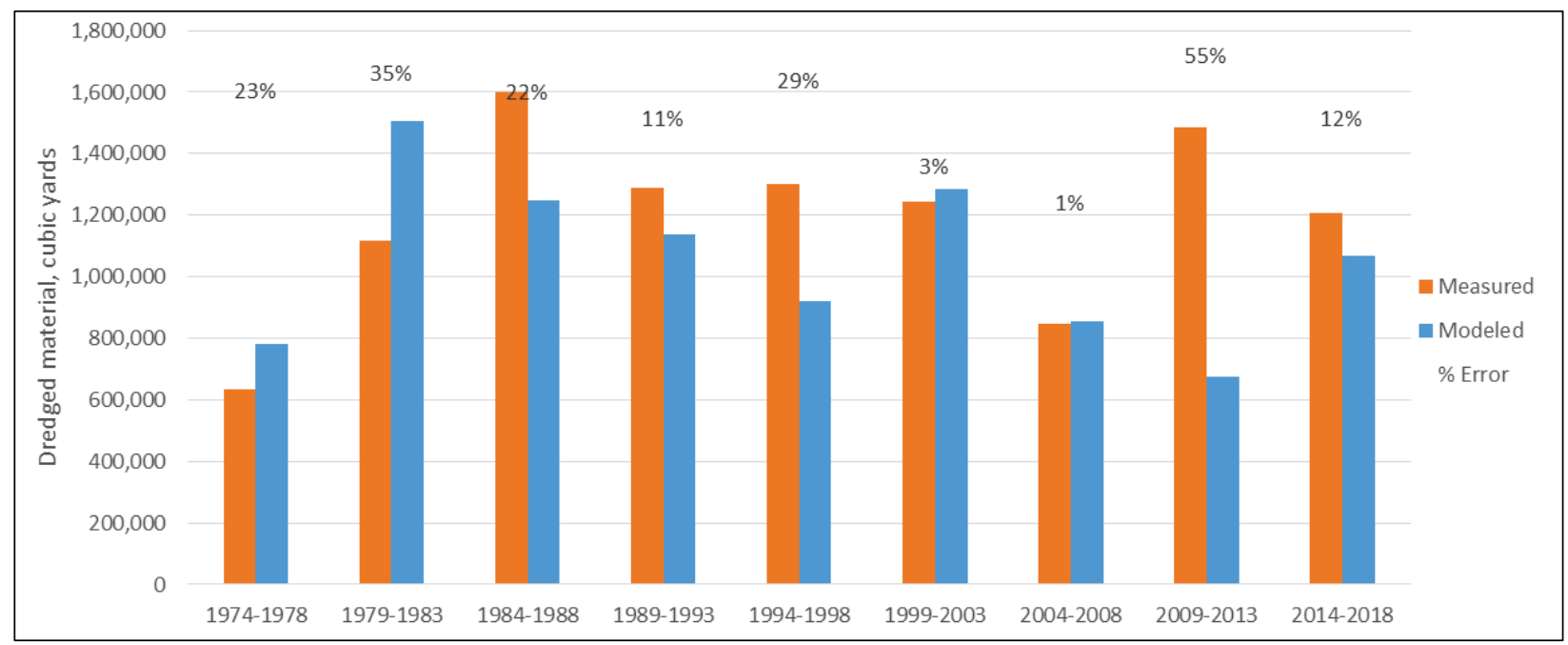

Figure 9. Total 5-year dredging quantities in Lower Pool 4, measured vs. modeled.

DISCUSSION: The development of this model has provided a tool that can be used to assess proposed changes to the river system or for forecasting future hydrologic scenarios. In future years, if measures are taken to reduce the incoming load at Durand (e.g. upstream bank stabilization or water retention), the model could be used to translate this reduction to a relative change in dredging quantities in Lower Pool 4. Additionally, during spring snow-melt planning in a given year, the 
model could be used to assess the probability of predicting above-average dredging quantities by simulating a forecast for the spring flood using analogous historic years. This approach could be improved upon further as a given flood progresses by utilizing real-time flow data along with the real-time sediment data that will become available through the USGS monitoring effort. Also related to data collection, this model may provide insight into help quantifying the unmeasured load or the discrepancies between dredge volumes and estimated sediment delivery. Finally, the model could be used to identify feasible alternatives for dredging practices such as increasing the size of the sediment trap or performing dredging at more strategic locations. This RSM modeling effort should improve dredge volume predictions and associated costs to the MVP and USACE by making better, more efficient operations and planning decisions on an annual basis.

ADDITIONAL INFORMATION: This RSM-TN was prepared by Alex Nelson alexander.g.nelson@usace.army.mil, USACE Mississippi Valley Division St Paul District (MVP). This study was conducted as an activity of the USACE National Regional Sediment Management (RSM) Program, a Navigation Research, Development, and Technology portfolio program administered by Headquarters USACE. Additional information pertaining to this RSM TN can be obtained from Mr. Nelson. For information pertaining to the USACE National RSM Program, please consult the RSM website (http://rsm.usace.army.mil) or contact the USACE National RSM Program Manager, Dr. Katherine Brutsché Katherine.E.Brutsche@usace.army.mil.

This RSM TN should be cited as follows:

Nelson, A. 2020. Development of a HEC-RAS Sediment Model for the Chippewa River, Wisconsin for Use in Predicting Future Dredging Activities. ERDC/TN RSM-20-8. Vicksburg, MS: U.S. Army Engineer Research and Development Center.

\section{REFERENCES}

Abraham, D., J. Hendrickson, K. Jones, A. R. Jackson, and T. McAlpin. 2020. Bed-load transport measurement on the Chippewa River, Wisconsin, during a high flow, using the ISSDOTv2 method. ERDC/TN RSM-20-3. Vicksburg, MS: U.S. Army Engineer Research and Development Center.

Dean, David J., et. al. 2019. Measuring Suspended-Sediment Concentrations, Grain Sizes, and Bedload using Multiple Single-Frequency Acoustic Doppler Profilers and Echologgers in the Lower Chippewa River, Wisconsin. U.S. Geological Survey (USGS). Active Study. https://www.usgs.gov/centers/sbsc/science/measuring-suspendedsediment-concentrations-grain-sizes-and-bedload-using?qt-science_center_objects $=0 \#$ qtscience_center_objects.

Ferguson, R.I. 1986. "River Loads Underestimated by Rating Curves.” Water Resources Research, 22(1): 74-76, Conference Paper.

Nelson, A. 2019. Modeling Mississippi River Dredging Strategies after the Lock Closure at Upper St. Anthony Falls. U.S. Army Corps of Engineers (USACE). Conference Paper, SEDHYD.

Rose, W. J. 1992. Sediment transport, particle sizes, and loads in lower reaches of the Chippewa, Black and Wisconsin Rivers in Western Wisconsin. Water Resources Investigations Report. U.S. Geological Survey (USGS).

U.S. Army Corps of Engineers (USACE), Hydrologic Engineering Center (HEC). 2019. HEC-RAS, River Analysis System. Version 5.0.7.

U.S. Army Corps of Engineers (USACE), Rock Island District. 2019. The 9-foot Channel Project. Rock Island District website. https://www.mvr.usace.army.mil/Missions/Navigation/NESP/The-9-foot-Channel-Project/. Accessed 2019. 
ERDC/TN RSM-20-8

September 2020

U.S. Army Corps of Engineers (USACE), St. Paul District. 2017. Lower Pool 4 Dredged Material Management Plan. Draft Report.

U.S. Army Corps of Engineers (USACE). 2004. Upper Mississippi River System Flow Frequency Study. Report stored on Rock Island District website. https://www.mvr.usace.army.mil/Missions/Flood-Risk-Management/UpperMississippi-Flow-Frequency-Study/

NOTE: The contents of this technical note are not to be used for advertising, publication or promotional purposes. Citation of trade names does not constitute an official endorsement 